\title{
Mulheres pobres que amam demais: a vida dos direitos e das políicas sociais
}

Adriana Fernandes ${ }^{2}$

Resumo: 0 artigo se dedica a discutir a relação entre acusações morais, compaixão e as políticas de direitos referentes a grupos em situação de vulnerabilidade, no caso, mulheres acolhidas em um abrigo municipal no Rio de Janeiro. Abordaremos o cenário de direitos e de políticas em condições de precariedade, tendo como fio condutor os jogos de linguagem e as disputas nesse cotidiano.

Palavras-chave: abrigos - vulnerabilidade - gênero - direitos - compaixão

\section{Poor women who love too much: the life of social rights and policies}

Abstract: This paper is dedicated to discussing a relationship between moral accusations, compassion and how copyright policies of vulnerable groups, in no case women taken to a municipal shelter in Rio de Janeiro. Disorder or scenario of rights and policies in precarious conditions, having as a thread the language games and as disputes in this daily life.

Keywords: shelters - vulnerability - gender - rights - compassion

1 Esse texto é fruto de pesquisa financiada com bolsa FAPERJ e contou com a interlocução do coletivo de pesquisa Disturbio (UERJ/UFRRJ). Sou grata a Patricia Birman, a Mariana Ferreira e a Paula Lacerda pela leitura e comentários; agradeço a Cibele Rizek e a Isabel Georges pelo convite para apresentar um primeiro esboço no encontro organizado pelo LMI/SAGEMM-FLACSO, em Buenos Aires; agradecimento especial a Adriana Vianna.

2 Programa de Pós-Graduação em Ciências Sociais (PPCIS) - Universidade do Estado do Rio de Janeiro (UERJ) - Rio de Janeiro - Brasil - dricafernandes@yahoo.com.br 
Durante o trabalho de campo em um abrigo municipal para mulheres, no Rio de Janeiro, me chamou a atenção o comentário recorrente realizado pela diretora e direcionado a um grupo numericamente significativo que chegava a esse equipamento: elas seriam "mulheres que amam demais". A esta caracterização somou-se a notícia de que aproximadamente metade das abrigadas que passavam pela Unidade de Reinserção Social Rose Marie Muraro portavam sífilis: "Largam tudo, os filhos, a família, para ir atrás de homem e ficar mamando pau na Central!"3.

Juízos morais e normativos sobre o corpo feminino e suas formas de existência, como sabemos, foram inscritos como política de população no Brasil por meio da instalação, não sem resistências (Rago, 1997; Chalhoub, 1996; Lopes, 2000), de uma ordem médica conjugada à norma familiar (Costa, 1979). A mãe dedicada, circunscrita à esfera doméstica, responsável pela reprodução, higiene e formação dos filhos foi um dos pilares da política higienista desde o final do Século XIX, intensificando-se na reforma sanitária, permanecendo até o regime biomédico. Esse conjunto teria como missão final engendrar uma nação saudável (Lima; Hochman, 1996; Seyferth, 1996; Stepan, 2004; Costa, 1980). Tal padrão normativo, todavia, esteve circunscrito aos estratos médios e urbanos, não se podendo imputar a mesma normatividade às camadas populares ${ }^{4}$ (Fonseca, 2004; Engel, 2004; Soihet,2004).

Os vários casamentos entre as mulheres pobres demonstram como uma economia moral menos estreita marcava essas camadas urbanas. Se a vida sexual era mais movimentada, a maternidade se constituiu como um ponto fundamental no processo de disciplinarização dos corpos e de controle. A mãe das classes populares e de cor precisou ser escrutinada, em especial, pelo potencial papel de impureza e contágio que carregava em seu corpo negro ou mestiço. Sabemos como a eugenia marcou o processo de formação das cidades brasileiras, sendo ponto central na construção do imaginário da nação civilizada e moderna, protegida de degenerescências morais ou epidêmicas (Stepan, 2004; Seyferth, 1996).

Se as ideias de perigo e de contágio permanecem imputadas aos corpos das mulheres e mães negras e pobres, tidas como "relapsas" ou "suspeitas" como bem mostra a tese de Camila Fernandes $(2018)^{5}$, nas reflexões a seguir produzi-

3 Os nomes das pessoas e dos equipamentos da prefeitura que aparecem no texto foram trocados, conservei apenas um apelido tal como era.

4 Utilizo os termos camadas populares e estratos médios ou burgueses durante o texto para fins de análise, creio indispensável observar que esse recorte não ignora a heterogeneidade presente nesses estratos.

5 Nessa etnografia, a autora reune e analisa acusações morais recentes em torno da sexualidade e maternidade entre jovens e mulheres de camadas populares em uma favela no Rio de Janeiro. A "mãe nervosa", a "mãe abandonante", a "novinha", todas figuras da "causação" surgem como categorias que reatualizam marcadores morais, ao mesmo tempo que, incorporam direitos e políticas públicas para mulheres nos mais variados registros. A luta por uma vaga na creche como um direito, os exames de DNA para 
das com base no trabalho de campo em abrigos municipais da cidade do Rio de Janeiro, novas disputas em torno de direitos e moralidades foram incorporadas nesse conjunto. Raça, gênero, poder, maternidade, sexualidade e desejo surgem imbricadas ao repertório de políticas e de direitos. Proponho explorar como esse reportório de políticas e direitos relacionado à vulnerabilidade ou ao sujeito moral da vulnerabilidade é manejado de forma a se reerguer ou retomar a vida6 por outros caminhos, com novas parcerias, ou ao menos para se conseguir dar um tempo das situações aflitivas, persecutórias e de precariedade material, nas quais ameaças e agressão física e psicológica mantêm-se muitas vezes a espreita.

Como apontaram as autoras antes mencionadas, pensar outros padrões de normatividade e as disputas morais em torno destes, permanece fundamental para entender como mulheres pobres inventam e experienciam suas relações, casamentos, modalidades de família, maternidade, redes de apoio e o que este conjunto é capaz de interrogar a pobreza, as desigualdades, sua produção, as rupturas e as continuidades na sociedade brasileira.

Uma primeira observação que o trabalho de campo com mulheres em um abrigo municipal no Rio de Janeiro, início do Século XXI, nos faz perceber, é que tanto os discursos e práticas referentes ao higienismo e aos dispositivos disciplinares, quanto as formas libertárias, menos normativas, de vivenciar a sexualidade e as relações, são capazes de combinar e de conviver. A linguagem dos direitos, nesse conjunto, pensados como práticas e modalidades de encarnação, na esfera pública, de conflitos e formas de existência até então silenciados,

reconhecer a paternidade, os usos de métodos anticoncepcionais ("a injeção no posto"), as falas sobre a violência doméstica, as denúncias de maus-tratos de crianças e violência sexual, os questionamentos em torno do machismo, enfim, um mundo de exigências que adentrou via políticas de direitos, nas camadas populares, recompondo esses conflitos e os poderes envolvidos, (re)colocando velhos e novos dramas, termos e dilemas. Nesse conjunto, não podemos deixar de assinalar, atravessando esse cotidiano, o alto número de mortes e assassinatos perpetrados pelo Estado.

6 Expressões que escutei com alguma frequência e que considero centrais no cotidiano dos abrigos estarão grafadas em itálico e não remetem a diálogos estabelecidos e registrados seguindo uma situação ou cena específica, estas aparecerão grafadas sempre em aspas; a intenção, ao trazê-las em itálico, é de desenhar um campo ou ambiente semântico, assim, expressões e palavras recorrentes são utilizadas com alguma liberdade, na tentativa de demarcar sentidos, apropriações, criações de linguagem que me parecem significativos para entender as questões que apresento. Nessa pesquisa não fiz entrevistas ou utilizei gravador, tentei registrar o que escutei ou conversei em geral algumas horas após estar no abrigo ou, no mais tardar, na manhã do dia seguinte. $\mathrm{O}$ campo foi realizado em dois abrigos, um feminino e um masculino, ambos próximos a área central da cidade; antes de fincar neles, foram feitas visitas em um abrigo de mulheres em situação de violência e ao abrigo de Antares, conhecido como Abrigão, com muitas denúncias de superpopulação, casos de tuberculose, presença do tráfico etc., ambos os abrigos estavam localizados na zona oeste da cidade. Estive nos abrigos em períodos dos anos 2015 a 2016, a pesquisa teve que ser interrompida após eu trazer percevejos de cama para a minha casa. Com Raquel Carriconde dividi o início do campo, seu trabalho resultou em tese de doutorado defendida recentemente no PPCIS/UERJ (Carriconde, 2019). 
resultam mesmo em uma ética do ordinário (Das, 2012) desenhada não por "representações dramáticas" e "lutas heróicas entre o bem e o mal", mas por "fios entrelaçados na trama da vida" (p.134). Nas palavras de Adriana Vianna (2013): “(...) a linguagem dos direitos reafirma dissensões morais, oferecendo espaço para que sejam tecidas contranarrativas e para que novos sujeitos se façam presentes em cenas públicas" (p.16).

Em tempos de agenda neoliberal autoritária, caracterizada pelo esvaziamento das políticas sociais, da precarização do trabalho e do agravamento das condições materiais dos pobres e mais pobres, tudo isso é alimentado por uma subjetividade empreendedora e meritocrática, porém, não devemos supor que nesse processo houve (e há) uma conversão irrestrita das camadas populares a tal racionalidade?. As observações de Veena Das e Shalini Randeria (2015) são aqui inspiradoras:

Não temos o desejo de romantizar os pobres ou de subestimar as formas pelas quais a pobreza pode corroer a capacidade de ação coletiva ou individual, mas parece-nos que uma compreensão da pobreza deve vê-la em relação aos estreitos laços com outras condições da vida, como a possibilidade de participação democrática, a erosão da infra-estrutura, a negação da cidadania como no caso dos refugiados, o efeito da raça e das políticas de encarceramento, ou o modo pelo qual os meios de subsistência podem se enredar o tráfico de drogas ou o vício ou são destruídos intencionalmente em nome do desenvolvimento ou do funcionamento do livre mercado. Em cada uma dessas constelações, podemos discernir as diferentes maneiras pelas quais a pobreza é vivenciada e até que ponto o potencial para a ação política (visto como o esforço para produzir um tipo diferente de cotidiano) é alcançado (p. 54$)^{8}$.

O artigo está divido em cinco seções, além desta introdução e da conclusão. $\mathrm{Na}$ primeira seção, destaca-se algumas características dos abrigos e suas diferenças por gênero, para isso, menciono os diferentes usos que os residentes fazem desse

7 Para uma discussão bibliográfica sobre o tema e por matizar a presença do mercado nas periferias nas últimas décadas remeto ao artigo de Miagusko, Jardim e Cortes (2018).

8 Os trabalhos de Patricia Birman (2019) e Camila Pierobon (2018) têm apontado o cuidado como um elemento fundamental para pensarmos uma ética do ordinário entre os pobres e que passa necessariamente pelas mulheres. No caso de Leonor, moradora de uma ocupação na cidade do Rio de Janeiro e principal interlocutora da tese de Camila Pierobon, o cuidado está nos modos como ela lida com as doenças graves da mãe em meio à precariedade da vida na ocupação (ameaças e conflitos de vários tipos, possibilidade de remoção etc.); e, igualmente, quando Leonor maneja todo um repertório mágico-religioso para reverter a prisão da filha. Sobre o tema do cuidado em um viés filosófico e associado à vulnerabilidade remeto à Sandra Laugier (2015). Nesse trabalho a autora enfatiza o papel fundamental das relações sociais para a análise. 
espaço, e faço uma apresentação das mulheres que ocupam o abrigo femino Rose Marie Muraro e as acusações morais das quais elas são depositárias. Nas seções seguintes trago algumas cenas etnográficas que acompanhei nos abrigos de maneira a mostrar como quatro residentes constituem seus modos de corpo compassivo e se combinam ao imaginário de políticas e de direitos para reivindicar melhores condições de existência, na linguagem nativa, com o desejo de "se reerguer".

Em termos mais explicitamente teóricos, a pista pela qual insistimos vem da proposição de Sergio Carrara (2015) de que o dispositivo da sexualidade de Michel Foucault (1979) estaria sofrendo inflexões importantes graças à "chegada" das minorias e de pautas identitárias na política e no Estado. Este protagonismo seria responsável por questionar a produção da vida inscrita na verdade sobre a sexualidade e sobre o sexo, e estaria experimentando arranjos sociais, econômicos, políticos, familiares e de construção de si que revolvem o próprio dispositivo. Por sua vez, o campo dos abrigos põe ênfase em como o corpo compassivo/ vulnerável e as disputas morais em torno da sexualidade feminina estão sendo afetadas por esses novos repertórios de direitos.

\section{As formas materiais do abrigo por gênero}

Diferentemente do abrigo para homens, o abrigo feminino tinha sempre a porta de entrada fechada com cadeado, sendo necessário que um funcionário pudesse abri-la. $\mathrm{O}$ controle sobre as saídas das usuárias era muito mais rígido do que a realizada no abrigo de homens. As vagas para as mulheres que esperavam na fila do abrigo de origem eram em número muito menor do que as existentes no abrigo masculino. Ser portadora de sífilis ou HIV, por sua vez, não as impedia de vivenciarem uma intensa vida amorosa após a chegada nesse abrigo de origem, no qual se esperava de um a dois meses a distribuição para os abrigos disponíveis em outras partes da cidade. Como sabemos, é, muitas vezes, uma forma de proteção material e física contar com um parceiro "marido" quando se está na rua ou em condições econômicas mais delicadas. Os dispositivos de saúde e da assistência social presentes desde a entrada no abrigo funcionavam como uma nova tentativa de cuidado, mas também de enquadramento e controle desse corpo pobre feminino que se excede (Guimarães, 1996).

Por meio de passagens nesse campo dos abrigos proponho seguir as pistas dos enunciados - "mulheres que amam demais, largam família e filhos, e só querem mamar pau na Central" - suas apropriações e os efeitos na normatização e produção de corpos generificados e o que escapa desse enquadramento ou tenta escapar. Igualmente para pensar tais passagens como formas não pacificadas de habitar a cidade, se apropriar de políticas e exigir direitos. 
Como Michel Foucault (2010) observou, a cidade e seu desenho urbano foi fruto a partir da modernidade de formas de segregação originais: o corpo era percebido baseado em um ordenamento que seguia o modelo de evitação ao "corpo leproso", ou seja, era preciso retirar leprosos e anormais do convívio, afastando-os para lugares distantes da cidade. Com a epidemia da peste, esse modelo se transforma, e permanece até nossos dias. Qualquer corpo, alguns corpos mais que outros, em qualquer lugar, se torna suspeito. São reconhecidos como corpos passíveis de contágio e de transmissão, portadores de perigo sem saber. Com esse novo paradigma epidemiológico, uma série de práticas individualizadas, localizadas, de controle corpo a corpo, casa a casa, bairro a bairro se fixará como centro das políticas sanitárias e do higienismo vigentes até hoje.

Esse corpo feminino que se excede (Guimarães, 1996), demoníaco (Bretas, 1997), assombroso (Butler, 2014) e que é desde sempre uma ameaça ao ideário da mulher dedicada: “(...) elas largam tudo para ir atrás de homem”, “(...) amam demais", “(...) só querem mamar pau na Central”, “(...) deixam filhos e família e vão para seguir homem na rua”. Nas palavras também de Flora: elas têm no abrigo "a chance de se levantar", “(...) porque fica ali quem está querendo seguir, não fica quem está querendo sacanear; a gente agiliza os documentos para elas se reestruturarem".

Mas quem afinal são as mulheres que querem "sacanear" e quais as que se tornam objeto de reconhecimento de compaixão por políticas e agentes governamentais? As mulheres aptas a obter uma chance para se reerguer, se levantar através de políticas de vulnerabilidade são parte de um mercado de vulnerabilidade, que opera manejando marcadores morais, de raça e gênero. Os temas da impureza e contágio fazem parte do repertório cotidiano do abrigo feminino e passavam quase inaudíveis no abrigo masculino.

As exigências para a realização de exames e consultas formavam uma das jornadas principais do Rose Marie Muraro, assim como tirar os documentos e se cadastrar em algum banco de trabalho. $O$ tema do cuidado mediante recuperação de alguma enfermidade aparece, e se sobrepõe, à forma de recuperar o corpo visto inicialmente como "encardido", degenerado, ou ao menos para tentar reerguê-lo de uma perdição sem volta. Os corpos que não reconhecem esse traço de perigo ou que não se arrependem desse passado-presente podem ser considerados corpos indignos, corpos abjetos, corpos fadados à recusa. Vulnerabilidade e economia moral se somam às técnicas de cuidado, saúde, disciplinarização, controle e de descarte (ser "desligada" do abrigo), de maneira a produzir deslocamentos de enunciados, palavras de ordem e modos de vida. Ao mesmo tempo, a pauta de direitos e de acesso às políticas sociais 
complexificaram esse conjunto, propiciando que modalidades de gênero heterotópicas interroguem a cena política dominante.

A ideia de mulher guerreira, e que rápido desliza para brigona ou quizumbeira, "por onde passa arruma confusão" desdobra o estigma desse corpo que se excede, marcante desde o higienismo para uma bioidentidade pela vulnerabilidade que exige direitos, questiona a desigualdade e o caráter assistencialista que endossa a vitimização e a subalternidade, chegando até as políticas sociais.

\section{Corpo da Compaixão no limiar}

É tentando escapar das vozes que insistem em lhe visitar, que Brenda busca deixar a cocaína, parar com tudo, e faz planos para morar com Chaveirinho, que conheceu no abrigo da Ilha do Governador. Ela o chama de marido, diz que ele quer ter um filho seu, bem como desejam alugar uma casa no bairro de Santa Cruz, zona oeste da cidade, cerca de 80 quilômetros do abrigo onde estávamos. Brenda se recupera de uma internação de 10 meses, por conta de uma tuberculose. Por conta da turberculose diz que lhe sobrou 10\% de um dos pulmões. Vivia na Av. Brasil após largar o trabalho como endoladora de drogas na Fazendinha, Bonsucesso (na zona norte, bem próximo ao centro, conhecido pelos tiroteios, pela a presença de facções e de incursões policiais). Gosta agora de escutar "louvores", "esses do Irmão Lázaro e da Elaine [Martins/ex-ADUD, Assembleia de Deus dos Últimos Dias]". "A minha estoria está todinha nesse louvor". Tenta fazer com que eu escute, mas o rádio que ganhou de Chaveirinho e que ela feliz leva no quadril, falha; anoto os nomes dos cantores e digo que vou procurar na internet. "Porque meu problema é a-bs-ti-nên-cia" - diz alto, soletrando lentamente cada sílaba. "Tenho problema de nervos, sabe?"

Esperamos, as duas, a chegada de Chaveirinho. Ele vem sempre às $16 \mathrm{hrs} \mathrm{da}$ tarde. Vou ficando ansiosa percebendo ela ansiosa, já passa em muito da hora combinada e nada dele. "Ele ficou de me trazer cigarro, geralmente vamos até a praça”. Ele lhe paga um picolé ou um lanche. $\mathrm{O}$ assunto sobre Chaveirinho querer ter um filho é recorrente, Brenda a princípio não está favorável, já possui uma filha e justifica sua recusa dizendo ser muito ruim ter de ficar meses acordando de noite, sem poder dormir. Em outra ocasião conta que faz quatro meses que não vai ao posto de saúde receber a megadose do anticoncepcional, entretanto, não acha que esteja grávida. A barriga é porque está comendo muito - ela observa - aproveitando para elogiar a cozinheira do abrigo e relembrar a cozinheira do abrigo da Ilha, que era "sapatão, cozinhava muito, era muito gente boa”. Antes de disparar com Chaveirinho, mostra as várias camisinhas que a 
psicóloga acabara de lhe dar e comenta que esta marcou para ela fazer "aqueles exames". Chega Chaveirinho, ela me apresenta, ambos comentam sobre uma outra residente 9 , muito magra, pouco fala, sempre com cigarro na mão, geralmente apagado.

Brenda lembra então que já foi daquele jeito, aqueles meses todos, ela chegou a ter menos de $40 \mathrm{kgs}$, ficava na Av. Brasil depois que perdeu o trabalho na endola. Acabou conhecida no hospital, "conhecia todo mundo, falava com todo mundo". O médico lhe disse que teria que parar com tudo, ela tenta, desde domingo não colocou nada para dentro (estávamos na quarta-feira). "Quero parar mesmo" - ela repete. As educadoras e cozinheira escutam nosso diálogo e a incentivam com frases motivacionais bem distantes do programa de redução de danos, diretriz principal do Sistema Único de Saúde (SUS), que orientou as políticas sobre uso de psicoativos até as portarias de 2019, que indicam o modelo de abstinência. As frases motivacionais diziam mais ou menos assim: "(...) isso mesmo, tem que ter força de vontade", "(...) não desiste!", "tudo depende da força de vontade da pessoa", "tem que querer", "é uma questão de ter cabeça”. Comento se ela está frequentando algum CAPS AD (Centros de Atenção Psicossocial para tratamento de usuários de álcool e drogas) ou já frequentou. Ela diz que a psicóloga estava vendo isso. "Tenho problema nos nervos" - repete - a última vez que ficou sem tomar o remédio terminou seguindo uma voz que lhe dizia para tacar o cabo de vassoura em Chaveirinho porque ele queria proibi-la de fazer algo. Mostra suas mãos, negras e trêmulas, comenta que sente muita instabilidade nelas. "Já aprontei muito, beijei muito, agora quero me acalmar".

$\mathrm{O}$ abrigo de mulheres, diferentemente do abrigo dos homens, parece mesmo ter uma função "pedagógica". "Ali a gente orienta para as mulheres que querem seguir com as suas vidas" - repete Flora, a diretora mão forte e "mãezona", como algumas usuárias a chamam e que "gosta de trabalhar com a verdade" (palavras suas). Essa função "pedagógica”, portanto, como um checkpoint disciplinar/normativo, ao menos em termos de limitar ou dar um tempo dos perigos da rua e outras situações. Como uma chance de retornar ao papel de mãe e mulher ciosa de boas condutas. Brenda, algumas semanas depois, caiu na vida, reencontrou os amigos no bairro de Santa Cruz, fez noitada, Chaveirinho achando que não a encontraria mais. Tinha arrumado outras companhias, ele me disse inconsolável, o rosto inchado de uma noite insone.

9 A forma de chamar quem utilizava os serviços dos abrigos variava dependendo da situação e de quem o fazia, se técnicos ou os próprios “usuários", então, além deste, "usuário", escutei: "abrigado/a", "acolhido/a" e "residente". Aqui eles aparecerão como sinônimos, sem discriminação. 
Essa função "pedagógica" do abrigo - esse checkpoint disciplinar/normativo garantia, por sua vez, o manejo e a possibilidade de apropriações e usos diversos da linguagem de direitos. Foi dessa forma, manejando um novo código para escapar ou contornar de zonas de perigo que Brenda portou sua munição (em termos simbólicos) contra seu ex-parceiro que cria a sua filha, agora com 11 anos. Ao perceber que ele não iria facilitar seus encontros com a menina, acusou-o e afirmou que daria queixa da casa dele no Conselho Tutelar. A assistente social certamente logo veria que a casa do ex-parceiro era um "lugar insalubre para criar uma criança", "com esgoto saindo no quintal e outras coisas", ainda por cima ela - Brenda - contaria que não é o nome dele que consta no registro de nascimento da menina. A estória é embaçada - e isso é algo esperado - mas o importante é sublinharmos como Brenda sabe usar os dispositivos da assistência social para se defender de uma possível recusa do pai de não deixá-la vê-la após tanto tempo.

Para Sergio Carrara (2015), a partir de leitura da bibliografia sobre direitos e movimentos de minoriais pós-1988, o dispositivo da sexualidade (Foucault, 1979), a vontade de saber e de dizer a verdade de si pela sexualidade - estaria vivendo, no Brasil (e no mundo), inflexões importantes e estaria distante de uma dicotomia "avanços" versus "retrocessos". Essa vontade de dizer e falar sobre o si a partir da verdade do sexo/sexualidade se conjuga agora a um amplo repertório de direitos, de políticas sociais e de bioidentidades, responsável por produzir efeitos outros, assim como encena conflitos não disponíveis anteriormente:

(...) talvez mais importante seja o fato de que trabalhar no nível de tais políticas sobre a possibilidade de abordar o próprio dispositivo da sexualidade, indagando sobre suas fissuras, tensões e horizontes de transformação, em suma, sua própria historicidade. Em tempos em que a sexualidade e o gênero são matéria para afirmação de direitos humanos, continuaria o célebre dispositivo a articular com a mesma precisão uma anatomopolítica dos corpos a uma biopolítica das populações? Ou estaríamos assistindo, em seu interior, à implantação de um novo regime de sexualidade? E, nesse caso, quais seriam suas principais linhas de força? Em que pontos haveria rupturas e em que pontos, continuidade? (Carrara, 2015:325).

Seguindo a pista de Carrara, a apropriação desse repertório de direitos não se restringiria a marcadores reificadores de identidades, mas sugere que eles têm se constituindo como possibilidade de ampliação de direitos das minorias e como contornamento dos mecanismos da vida matável, vida nua, mecanismos de exceção (Agamben, 2004). Direitos e políticas são assim elementos que alimentam a arte de contornar (Telles, 2010; Fernandes, 2013) as ameaças que se 
apresentam ao cotidiano dessas populações. Proporcionando o combústivel da "máquina de curar" (Canguilhem, 2005) e do "fazer circular", ambos fundamentais na vida e no controle dos pobres desde a instalação do paradigma sanitário nas cidades e nas metrópoles.

A circulação não é ampla no sentido subjetivo, são redes que se tecem e se repetem, numericamente não são mundos tão diversos e heterotópicos, podem até envolver trânsitos translocais, circuitos que ganham força após os fluxos migratórios internacionais, igualmente suas interpelações e bloqueios. A circulação envolve senhas, interdições, paradas, tempos de espera, intervalos, novos fluxos e intensidades. Todo um circuito está presente, mas o risco de ser detido em algum dos pontos permanece sempre no horizonte e, muitas vezes, é isso o que ocorre.

No caso de Brenda seu ponto de parada foram os 9 meses que passou no hospital Raul Gazzolla, em Acari, na zona norte do Rio de Janeiro. Lá ela gostava de dizer que tinha conhecido todo mundo, ao final perdera um pulmão, ficou muito magra, e estava ali, no abrigo, procurando se "reerguer", escutando louvores, esperando o cigarro de Chaveirinho, seu companheiro conhecido semanas antes no abrigo da Ilha, cada qual esperando uma vaga, e agora planejavam alugar uma casa em Tancredo Neves, zona oeste, para morarem os dois. Chaverinho e ela fariam bicos pela cidade, como ela já os fazia. Quem sabe Brenda conseguiria um benefício (BPC). Embora ela fizesse questão de trabalhar, como gostavam de frisar. Eu tentando convencê-los de que o benefício era um direito de Brenda, e isso não a impediria de trabalhar no mercado informal, quem sabe entrassem em um cadastro do Minha casa Minha vida, também na zona oeste, lá perto de onde tinham amigos e planejavam se estabelecer.

\section{Corpo da compaixão e direitos}

Assim como Brenda, que manejou os enunciados "ambiente insalubre" para convencer seu ex-parceiro a aceitar suas visitas à filha e a falsa paternidade, Simone, outra residente, recém-chegada, também procurou se defender das acusações de Flora diretora, logo que esta levantou a suspeita de que ela, Simone, poderia perder a guarda dos dois filhos. O clima não é dos melhores, Simone logo que chegara da rua interrompeu o atendimento de uma nova usuária que era recebida naquele momento. Queria saber se elas, a diretora e a psicóloga, poderiam lhe informar se a van do abrigo, que é responsável pelo transporte de usuários e residentes conforme deliberação da direção, a levaria no dia seguinte até a Defensoria Pública do Estado para ela pegar as certidões de nascimento dos filhos. Flora se exalta com a interrogação de Simone, diz que a van não 
estará disponível porque na verdade retonará com ela de volta para o abrigo de origem (na Ilha). E foi dessa forma que Flora comunicou a Simone que não a aceitaria mais no Rose Marie Muraro. Tento convencer Simone, sem sucesso, a conversar com Flora sobre seu desligamento do abrigo e o retorno ao acolhimento de origem, e sua provável longa espera (que podia chegar nessa época a dois meses) para ser realocada em um outro equipamento.

Mas Simone não parece preocupada com a volta para o abrigo que é superlotado e as condições - segundo as próprias abrigadas (e abrigados) - não são nada boas. Marcando em sua fala o deles da sentença: "É que aqui eu estou sob a lei deles" - Simone explica que o principal é que os filhos estão bem. Encontram-se em uma família acolhedora1o, de maneira transitória, “(...) eles estão muito bem, a família é ótima, estão mais calmos”. E ela está positivamente impressionada com a ideia de que o ambiente é mesmo importante, porque as crianças andavam muito nervosas por causa dos tiroteios e agora estavam bem. Tem como plano conseguir um trabalho e alugar uma casa. Seu marido segue preso, uma facção rival a dele tomou o morro, a permanência da mulher e das crianças na casa se tornou desde então inviável.

Manejando a linguagem dos direitos, Simone reclama, na frente de todas, que o abrigo não é aquilo que prometiam. Flora, a diretora, rompe de sua mesa e vem interpelá-la. Termina por encostar a mão no braço de Simone, um gesto que seria corriqueiro para chamar a atenção do próximo para o que se quer dizer, mas que naquele contexto significava um gesto de violência e ameaça, e lhe diz, novamente, que o juiz pode tirar os filhos de Simone. Esta fica furiosa. "Pesquisadora, você é testemunha, ela não pode fazer isso comigo, não pode botar a

10 Uma matéria no site do Conselho Nacional de Justiça, em 2017, explica tal modalidade: "As famílias acolhedoras se responsabilizam por cuidar da criança até que ela retorne à família de origem ou seja encaminhada para adoção. No Brasil existem mais de 46 mil crianças e adolescentes em situação de acolhimento, que vivem atualmente nas quase 4 mil entidades credenciadas junto ao Judiciário de todo o País, conforme dados do Cadastro Nacional de Crianças Acolhidas (CNCA) (...). (...). De acordo com o censo do Sistema Único de Assistência Social (Suas) de 2016, o serviço de acolhimento está presente em 522 municípios brasileiros e, segundo o Ministério do Desenvolvimento Social (MDS), há 2,341 mil famílias cadastradas para acolher 1,837 mil crianças e adolescentes. (...). A criança ou o adolescente é encaminhado a um serviço de acolhimento quando se encontra em situação de risco, teve seus direitos violados e foram esgotadas as possibilidades que permitiriam colocá-lo em segurança. Quase sempre o acolhimento ocorre quando o Conselho Tutelar entende necessário o afastamento do seu convívio familiar e comunica o fato ao Ministério Público, prestando esclarecimento sobre os motivos de tal entendimento e sobre as providências já tomadas no sentido da orientação, apoio e promoção social da família. Para ingressar no programa, a futura família acolhedora passa por avaliação e treinamento e pode receber crianças em casa por um período que varia de seis meses a dois anos. Esta família terá uma ajuda de custo de um salário mínimo por mês". Disponível em: <http://www.cnj.jus.br/noticias/cnj/85134-cnj-servico-o-que-sao-familias-acolhedoras>. Acesso em: 21 mai. 2019. 
mão em mim". Estou entre as duas, a situação é tensa, o abrigo fica em uma casa pequena, embora de dois andares, suas áreas eram espremidas, muitas vezes, se fez presente um ar denso.

Simone dispara pelas escadas em direção ao quarto coletivo que fica na parte de cima da casa. Flora desfia a ficha de Simone para mim e de forma que todos escutem. "A fiha não quer ficar com ela, porque aonde vai arruma barraco, a filha disse que não aguenta mais". Segundo Flora, a mãe era "conhecida da Secretaria desde 2000, para na rua desde esse tempo, depois vai para algum equipamento, depois volta para a rua". Simone agora desce a escada tão possessa quanto antes. Sobre o que ela disse da filha responde que "não tem nada a ver", "é outra coisa". "Eu não sou população de rua, o juiz vai logo ver que sou boa mãe" - replica. Achou inclusive que ali no abrigo aprenderia coisas, mas percebeu que as oficinas não eram o que prometiam. Pede para eu ir com ela ver o cartaz com a programação das oficinas na sala de atendimento. Ali ficam uma ou duas pessoas trabalhando - técnicos/educadores e a diretora - às vezes passam o tempo fazendo artesanato, nesse dia pintavam palhacinhos para uma festa de aniversário do filho da educadora. Simone pede para eu acompanhá-la e mostra o cartaz que vai lendo na frente de Flora diretora e de Goreti, educadora, com as oficinas. "'Oficina Dia de beleza"' - ela diz e completa em tom de queixa: "Poxa, como a gente pode fazer uma oficina de beleza se o abrigo não oferece um alicate?!”; “'Dia de Passeio", tudo bem, saíram uma vez, foi ótimo, foram passear na Lagoa [Rodrigo de Freitas, área abastada da cidade], aliás, os educadores são ótimos” - frisa, “(...) não tem nada o que dizer deles, aliás, não tem nada do que dizer de todos ali”. Goreti e Flora não reagem mais à provocação de Simone, concentradas se mostram na pintura dos palhacinhos. Simone me puxa para fora da sala, para o hall que é aberto.

Começa um bate-boca mais ameno com quatro das residentes que estão por ali - nesse espaço há uma mesa coberta e um espaço aberto onde é possível fumar um cigarro e ver o céu - das doze que ocupam, naquele momento, o abrigo. Alguém acusa Simone de acender a luz quando acorda, mesmo que ainda esteja escuro, faz barulho, não se importando com as outras residentes. Ela justifica sua atitude: como ela conseguiria botar a roupa para sair se não consegue enxergar no escuro? E completa em alto e bom tom que ela não precisa "puxar saco de ninguém", "nem da Dona Flora". As mulheres estão sentadas no hall, não discutem, parecem impassíveis frente aos comentários de Simone, que continua: "porque não acho certo fazer do abrigo hotel". E agora em voz baixa, sobre Brenda: "Ela é uma que adora dizer 'ah que banho maravilhoso, que comida, que cama quentinha". Porque disseram que o abrigo seria para conseguir os 
documentos, uma vaga de trabalho e assim alugar uma casa. Flora reaparece, e não está mais contida: "Querida, escuta bem, se o prefeito quiser que você fique aqui, mas se eu não quiser, você não fica - você entendeu? Se o cara do morro quiser que você fique aqui, mas se eu não quiser também, você não fica - você está entendendo?". Flora trabalha há muitos anos no abrigo e é originalmente nascida e criada num morro localizado próximo dali.

Segue o bate-boca, Flora esbraveja: "Ah como ela é vítima, ah como ela é vítima!". De repente o telefone fixo do abrigo toca, o clima de tensão é suspenso, do outro lado da linha está a mãe de Simone querendo falar com ela. Goreti educadora avisa que ela teria que falar rápido com a mãe, não poderá ficar meia hora ocupando o telefone como ela fez no dia anterior. E Simone: "Dá licença, será que posso conversar com ela no particular?”.

Mais do que apenas uma "conhecida da assistência" que "por onde passa arruma confusão" Simone encarna, pelos menos nessas passagens que eu acompanhei pelo Rose Marie Muraro, a interrogação, quase uma afirmativa, de Sergio Carrara, já mencionada, de que haveriam inflexões no dispositivo da sexualidade que apontam para a presença de outras linhas de força e disputas. Nas considerações finais retornaremos a essa questão.

\section{Corpo máximo da compaixão}

E é com sarcasmo que Marli diz que o Bolsa Família que recebe está mais para "Bolsa Farinha", porque o benefício mal dá para tomar algumas cervejas com salgado em um bar. Marli é etilista, consome diariamente muitos remédios, seu corpo é o corpo exemplar do dispositivo das agências de direitos humanos, o corpo reificado da compaixão. Negra, já parou na prisão por "puxar a faca" para a dona da pensão em que morava com o marido e a mesma vir a óbito; anos depois, foi presa de novo após sair pela rampa do Extra, com uma peça inteira de carne sem pagar. O segurança seguiu atrás de Marli que acabou detida, agora as passagens pela psiquiatria fizeram com que ela fosse solta, eis que chegou no abrigo e Flora se esmera para conseguir reintegrá-la à família, realizar os exames que precisa e levá-la ao Centro Psiquiátrico do Rio de Janeiro (CPRJ) para que possa refazer a medicação. No meio do percurso até o CPRJ, na van da Secretaria de Desenvolvimento Social, uma parada na praia do Leme porque Marli queria muito ver o mar.

O "Bolsa Farinha" portava não apenas uma face crítica, assuntos de ordem doméstica e da maternidade estavam presentes, como ela revelou em seguida ao tentar convencer uma de nós a ir no Saara (centro comercial localizado no 
centro da cidade e com mercadorias com preços mais em conta) quando o dinheiro do BF saísse, quem sabe por lá dava para comprar uma mochila que a filha lhe pedira (seria para a neta). Marli me pergunta se tenho carro, na época da pesquisa eu tinha, disse então que sim, me pediu para que pudesse ir com ela até Bangu ver essa filha e levar o presente para a neta. Eram tentativas de reaproximação de Marli com Luana. Concordei que podia levá-la. Dias após esse combinado um educador e Flora perguntaram para mim se era verdade que eu estava combinando de ir aonde a filha de Marli mora, e se mostraram céticos quanto à ela lembrar o caminho.

A situação de saúde de Marli se agravou, um dia sentiu tonteira com os remédios e terminou por se "jogar" ou "cair" - os verbos foram usados por duas técnicas quando contaram o fato, uma achou que foi intencional, a outra que fora efeito dos muitos remédios, "um apagão" - da escada do segundo andar que dá no hall do térreo. A situação de saúde de Marli não era das melhores, um longo percurso no etilismo, consumidora crônica de benzodiazepínicos (medicamentos para dormir), para labirintite, para os nervos e suas mãos trêmulas, tudo isso provavelmente consequência do longo tempo de medicalização. Foi ela uma vez que comentou para mim que não gostava do abrigo da Ilha [do Governador] porque lá tinha muita gente sempre falando alguma coisa, era um lugar "muito povoado", que "fazia mal a cabeça".

Marli era uma dessas abrigadas que deixaria qualquer antropóloga/o empenhada/o a conseguir acompanhá-la ou saber de seus percursos. Sua trajetória por vários equipamentos, duas passagens pela prisão, uma pelo manicômio, passagens pelo abrigo, o etilismo crônico, a pele negra, o roubo da peça de carne no Extra com fins comemorativos, queria fazer um churrasco, e sua saída altiva pela rampa do supermercado levantando a suspeita do segurança e em seguida sua detenção. Suas falas balbuciantes, ao mesmo tempo argutas. Era uma interlocutora que mobilizava a atenção minha, das técnicas, de Raquel Carriconde (pesquisadora que na mesma época fazia campo para o seu doutorado), bem como de outras residentes. Ao mesmo tempo, seus esquecimentos, olhares ao longe, corpo dopado, dificuldade de andar, pouca autonomia, desmaios, vertigens, inteligência e comentários, às vezes, enigmáticos, outras críticos e surpreendentes, a transformavam em uma lenda viva do corpo compassivo (Fassin, 2014):

Como Didier Fassin (2014) assinalou, o dispositivo estar doente, ou medicalizado, se tornou importante moeda de troca para as populações em situação de vulnerabilidade. Em Compaixão e repressão: a economia moral das políticas de imigração na França, o autor mostra como ocorreram as 
transformações de políticas de asilamento entre os anos 90 e 2000 . O humanitarismo que se intensificou nos anos 70 até os 90 (anos de ascensão do neoliberalismo) foi abalado com a "invasão" de imigrantes na Europa. $\mathrm{O}$ discurso dos direitos humanos passou a ser conjugado com o direito securitário, o que significou, em termos práticos, a diminuição da concessão de refúgios e asilos políticos, e o aumento de uma população migrante em situação irregular e precária. A partir dos anos 2000 o dispositivo de possuir uma doença severa passou a ser acionado como estratégia de permanência e de regularização de sua condição (em alguma das modalidades disponíveis, quase nunca em definitivo) (Fernandes, 2018:89).

O reconhecimento da compaixão e de um sujeito de direitos está, nessa genealogia, atravessado pelas marcas do adoecimento e a vulnerabilidade percebida mediante o sofrimento individual que procura redenção ainda nessa vida e nesse mundo. $\mathrm{O}$ testemunho desse turning point é imprescindível nessa construção (Côrtes, 2014) e para que as agências e políticas responsáveis por assegurar direitos e reparação se sintam obrigadas a agir ${ }^{11}$.

A importancia dos Benefícios e do Bolsa Família na construção de uma outra relação entre cidadania e Estado, o que alargaria o papel da sociedade política, nos termos de Chaterjee (2004) assinalado por Fabiana Jardim (2017). Segundo ela, a cidadania regulada que associava trabalho e direitos sociais veiculada desde Getúlio Vargas, nos anos 30, ganharia finalmente uma versão mais igualitária e efetiva de proteção e de garantia de direitos às camadas não apenas consideradas ativas da sociedade. "De fato, e articulada a outras políticas que têm alvo e beneficiário justamente os pobres ativos (refiro-me aqui ao Benefício de Prestação Continuada, por exemplo), o Bolsa Família se afirma como um programa que transforma de maneira incisiva as relações estado-cidadão (...)” (p.198). Jardim pondera que essa inclusão não está baseada, porém, no igualitarismo, mas na continuidade de políticas neoliberais, em que a inserção de massas marginalizadas socialmente se dá por meio do consumo e do mercado.

(...) nas duas últimas décadas, algumas táticas destravaram o governo dos pobres ativos brasileiros. Isso significa dizer que as práticas neoliberais adotadas no Brasil desde o final dos anos 1980, tornaram possível pela primeira vez que o estado tocasse o cotidiano e a vida de imensos contingentes da população que sempre estiveram aquém do direito. Assim, tais acontecimentos,

11 Para uma discussão sobre a compaixão a partir do diálogo entre budismo, filosofia ocidental, psicologia e direitos humanos ver Ferreira (2017). 
no que produziram de novos objetos e superficies de exercício de poder, têm transformado de maneira profunda a estrutura social brasileira, inclusive as relações entre estado e sociedade (Jardim, 2017:199).

A estória de Marli e o uso do Bolsa Família, todavia, significa uma curva, a meu ver fundamental nesse quadro. Bens, mercados e consumo, como mostrou Mary Douglas e Isherwood (2009) não podem ser pensados apenas pelo viés mercantil, mas pelos usos sociais de que são capazes, e o trocadilho do nome de Bolsa Família para Bolsa Farinha sempre me fez lembrar a importância que a farinha (de mandioca) possuiu na história dos pobres no Brasil (segundo Câmara Cascudo, "a rainha do Brasil") e como, de alguma forma, a mandioca garantiu o sustento e existência dessas camadas por séculos. No Rio de Janeiro, "farinha", no ambiente da drogadição, é também um dos nomes pelo qual se refere e se chama a cocaína.

Esse deslizamento entre o pó que esconde a fome por algum tempo e garante ficar "ligado" por turnos ou noites, mas que também sustentou a sobrevivência dos indíos no país durante a colonização tem com Marli, em sua condição de abrigada, a tarefa mais imediata de tentar uma aproximação com a filha. Essa possibilidade que o bolsa família insere no horizonte afetivo e doméstico-familar de Marli possibilita-nos de novo pensar nas apropriações e usos que esses bens de política social e distributiva ganharam desde a sua implantação $0^{12}$. Levar em conta esses usos pode nos ajudar a qualificar melhor os efeitos que eles possuem nos modos de subjetividade e como forma de entender a cidadania incorporada ao cotidiano das camadas populares, o que é convocado e mobilizado para além do mercado ou da financeirização da vida entre os pobres.

\section{Corpo da compaixão e cuidados}

E havia Mônica, corpo infame/corpo de um déficit cognitivo significativo, corpo que foi abandonado pela família na Avenida Brasil e vai parar no abrigo. Ficávamos muito tempo juntas na mesa comum do hall. Ou sentávamos próximas vendo novela na sala de $t v$. "Eu nunca vou sair daqui". No verão, as pintas vermelhas se alastraram pelo corpo, ela se queixou da intensa coceira. Seus

12 O BPC, o Benefício de Prestação Continuada, tem servido a diferentes fins; trabalhos apontam para os gastos relativos ao consumo doméstico e familiar como algo significativo (Costa, 2017; Pereira; Ribeiro, 2017). Ana Flávia de Oliveira, médica sanitarista, professora da USP, pesquisadora de violência contra a mulher, aproxima um estudo realizado em Bangladesh à condição da mulher pobre no Brasil. Nesse estudo, "mulheres beneficiadas por programas de microcrédito podem ficar mais vulneráveis porque tornam-se mais assertivas, têm o dinheiro delas e isso quebra a hierarquia de gênero" (Batalha, 2015:14). 
olhos grandes e atentos, que no princípio me intimidaram, depois pareciam sinalizar que eu era bem-vinda. Os olhares viraram, outras veze,s risos, e conversas deixaram de ser completamente ininteligíveis. Mais adiante, nos acompanhávamos mutuamente por lanches ou no jantar, vendo novela, aguardando a van para levar alguma residente a consultas ou agendamento para resolver pendências referentes a tirar documentos, entrada em benefício, ser atendida no Instituto Nacional do Seguro Social (INSS) para tentar uma aposentadoria por invalidez ou incapacidade. Às vezes ela colocava a cadeira ao lado de mim e de alguma outra abrigada com quem eu estivesse conversando, geralmente isso acontecia no hall do abrigo, lugar de passagem entre a sala onde ficava uma técnica e a diretora e o portão de saída.

O "eu nunca vou sair daqui" foi dito quando outras usuárias contavam sobre as expectativas alimentadas, principalmente pelo plano terapêutico, traçado entre elas e a psicóloga, sobre possibilidades de retomar a vida, um passo a passo para lidar com o cotidiano e traçar metas a médio prazo. Eu olhei para ela surpresa com a frase abrupta e dita de forma artificialmente natural e que parecia esperar que eu comentasse algo, mas eu não o fiz, embora tenha me deixado perturbada. Sua vida correria para sempre no abrigo? ${ }^{13}$

Um dia uma das duas educadoras da manhã não poderia comparecer, a outra teria que acompanhar uma usuária que precisava fazer exames de urgência (tinha um câncer de mama em estágio evoluído). $\mathrm{O}$ exame com o ginecologista na Clínica da Família do bairro estava marcado há alguns meses, ela estava com uma barriga pontiaguda protuberante, e reclamava de dores na mesma. Disse que eu poderia ir então, chegaria bem cedo no abrigo. Flora titubeou um pouco, mas depois concordou. O posto estava a dois quarteirões do abrigo. No dia fiquei preocupada em estar sozinha com Mônica. Flora e a educadora tinham

13 Em outro texto explorei quais os usos realizados pelos residentes dos abrigos, em resumo, podemos dizer que o abrigo é utilizado em três modalidades: a) como lugar de passagem, por conta de alguma situação extraordinária, porque se perdeu os documentos, brigou na família, teve que largar a casa por ameaças diversas, porque já vive na rua mas alguma situação fez com que procurasse dar um tempo no abrigo ou por motivo de doença; b) como "hotel", uma "segunda casa", possuindo um sentido pejorativo e era um termo que escutei bastante, utilizado como forma de fazer do abrigo um lugar para se recompor e onde se irá retornar outras vezes, um lugar que faz parte de um circuito de deslocamentos pela cidade, são os "conhecidos da assistência", como comentou Flora e outros técnicos, aproximando o usuário da imagem do vagabundo ou do malandro, daquele que "não quer nada da vida" ou é "folgado", noutros termos, próximo dos juízos que acompanham os indesejáveis, infames, não-disciplinarizados das cidades; e 3) "brinel", "junção de abrigo com pinel", nas palavras de um usuário repetindo o termo de um educador com muitos anos trabalhando no abrigo, possui um sentido de institucionalização e permanência, numa dimensão mais dramática e próxima do sujeito reconhecido pelo dispositivo da compaixão e das políticas de direitos humanos (Fernandes, 2018). 
contado que uma vez, de tanto insistir, elas deixaram Mônica sair para ir namorar. Dias se passaram alguém do CREAS do Centro ligou para a central de abrigos perguntando se conheciam uma garota etc. "Como ela estava encardida quando chegou no abrigo!”. E repetiram esse comentário algumas vezes de forma sarcástica. Um homem a tinha achado e levado ela no Centro de Referência de Assistência Social (CRAS) próximo da Providência. Mônica ficou pela Central naqueles dias, tinha dito que conseguiu namorar, e voltara para o abrigo "encardida". Fiquei com receio de que ela pudesse sair pelas ruas próximas, e eu não teria pernas para segui-la, então pedi para segurar sua mão logo que viramos a esquina, eu segurei firme, ela me olhou com surpresa, depois um riso travesso, eu continuei séria, seguimos até a Clínica da Família.

E foi alentador como lidou com as instruções de cores, cada cor um morro ou área da região, a Clínica estava ocupada por mulheres, muitas com crianças e bebês, agentes comunitários de saúde com suas pranchetas, seguranças, alguns poucos homens e mulheres dormiam nas cadeiras em frente às atendentes em seus computadores e o sempre mencionado SISREG (o sistema em rede do SUS que agenda as datas das consultas e os lugares para onde o paciente será encaminhado). Em meio a tudo isso, conversas entrecruzadas, conhecidos que se viam no posto, mulheres grávidas. Subimos até a sala onde seríamos atendidas por uma enfermeira. Antes na fila, Mônica olhou para um homem que sentara a seu lado, ele puxou conversa, ela sem cerimônia anunciou: “Estou grávida!". Ele arregolou os olhos, "Verdade?". E virou-se para mim para tentar alguma cumplicidade, me fiz de desentendida.

Já na sala com a enfermeira eu expliquei que era pesquisadora e que a educadora social do abrigo que viera teve que acompanhar outra residente e a diretora, a psicóloga e assistente social, cada qual estava com algum compromisso inadiável. Mônica então respondeu que não era virgem, mas não disse que estava grávida, os estagiários e a enfermeira de qualquer forma ficaram nervosos. “Como assim?!", e se dirigiram a mim, eu disse que não saberia responder e ligaria para Flora para perguntar. Pelo celular, Flora confessou que não tinha certeza e isso motivou uma silenciosa onda de pânico entre os técnicos da sala. Indaguei se não achavam melhor fazer o exame do abdômen porque era essa a queixa principal nas últimas semanas. A enfermeira disse que caso Mônica estivesse grávida, o exame poderia prejudicar a gravidez e resolveu chamar o médico que conhecia a paciente, assim ela foi encaminhada para a sala de exames, nesse outro recinto uma técnica recolheu o sangue, todos os resultados deram negativo e retornamos a sala de consulta. A enfermeira resolveu que não faria a ultrassonografia, nem o preventivo, e reagendou o exame. 
Como Lilia Lobo (2008) inventariou em trabalho precioso as formas da loucura e dos anormais no Brasil, os corpos dos portadores de deficiência, nesse caso, o corpo e a sexualidade da mulher portadora de retardo foram desde os Séculos XVIII, vistos como monstruosidade e sacralidade, ao mesmo tempo. A monstruosidade ganhará contorno de degenerescência com as teorias de eugenia do Século XIX, em seguida, as mais diferentes lutas em prol de minoriais, incluindo os deficientes entrarão em voga na segunda metade do Século XX, mas mesmo ainda hoje, a maternidade ou o desejo sexual e o erotismo dos deficientes sobrevêm quando signos de práticas de desejo e de vida permanecem objeto de apagamento.

No abrigo não era diferente, o rompante para namorar fez com que as técnicas abrissem o abrigo e deixassem Mônica sair pelo mundo. Até que alguém a levou a um CRAS e ela retornou para o Rose Marie Muraro. Esse retorno foi sempre lembrado pelas técnicas por ela ter voltado "encardida". A rua e sua sexualidade (não atrelada ao casamento ou a relações fixas) perduram ainda como impurezas na trama sanitária, da assistência e da saúde, mas o contra-ataque dela como alguém que não é mais virgem, ou que está grávida, ou que vai permanecer para sempre no abrigo, colocam questões sobre a presença dos "sem família" e "deficientes" em equipamentos do Estado. São os embebidos no Estado (Birman, 2018), a vida experienciada em seu interior, o Estado domesticado, a vida tutelada como direito.

Na Reforma Psiquiátrica, o incentivo a autonomia é um de seus pilares. O objetivo é produzir uma sociedade livre de todos os tipos de manicômios, portanto, produzir sujeitos autônomos e que possam viver em redes (de assistência, de saúde, familiares etc.). Os "sem família" colocam outras questões como Mônica o fez, pretendem se instalar no Estado para sempre, agora não como pedinte ou mendicante, mas como alguém que precisa de cuidados, diz isso quando reclama e mostra as pintas vermelhas que coçam e que não deseja mais ficar pela rua.

\section{Conclusão: Os clamores do abrigo}

Brenda, Simone, Marli e Mônica, institucionalizadas, mas por diferentes graus de vulnerabilidade, lidam com imperativos disciplinares e acessam direitos e políticas (mesmo que atravessados por precariedade e vida nua). Recaem na vida desviante, na vida do excesso, são mulheres pobres que amam demais. A educadora da noite, Vania, insiste para que as residentes evitem juntar colchão durante o sono porque teve gente reclamando que não conseguiam dormir durante a noite. "Ninguém aqui está em casa, gente, vocês aqui estão dividindo um lugar por um tempo, 
precisam respeitar o espaço uma da outra”. E que não deixassem calcinhas sujas na cama: "(...) porque ninguém precisa dormir com cheiro de bacalhau na cara; desculpa aí pesquisadora!". "E nada de ficar fumando na janela do quarto, seja lá o que for, nem deixar seus pertences espalhados pelo chão ou em outras camas".

Segundo Vania, era necessário puxar essas "reuniões de comportamento" quando sentia que as coisas estavam correndo de maneira "muito solta". Explicou que trabalha ali como educadora social do noturno tem alguns anos, conseguiu a vaga porque era egressa de presídio. A ideia de empregar ex-presidiários nos Centros de Acolhimento se deu na gestão do ex-prefeito César Maia. “Como uma forma de aproximar funcionários e acolhidos" - ela justificou.

O abrigo feminino mais do que encarnado na diretora "mãezona" Flora, me parece melhor condensado em Vania, a educadora da noite. Ou pelo menos é esta que funciona como um contraponto fundamental à Flora e sua maneira de levar o abrigo a "mãos de ferro". Como bem comentou Walter Benjamin (1987 [1934]) sobre os ajudantes, personagem que aparece frequentemente na obra de Kafka, e que seriam as únicas criaturas a terem êxito de escaparem do círculo familiar e que se parecem como um "grande novelo", dessa forma, são capazes de encontrar saídas para continuar a narrativa ${ }^{14}$ :

Vania conduz as residentes em um misto de correr solto e com auxílio de marcadores disciplinares pontuais, menos disciplinares e como produção de subjetivação. "O cuidado", "a consciência”, "o levar em consideração" eram palavras sempre usadas em suas reflexões enquanto conversávamos sobre o Rose Marie Muraro. Assim, o Centro de Acolhimento aparece como um ponto de checagem (checkpoint) seja como uma chance de reinserção (Carriconde, 2019), seja para minimizar a atração pela vida degradante (Scabio, 2013), a condição nervosa ou os estados nervosos (Duarte, 2010; Fernandes, 2017), os traços da vida infame (Foucault, s/d) ou, de modo mais concreto, na linguagem de Flora, diretora: "de parar de arrumar confusão por onde passam".

Habitar ou passar por abrigos é, portanto, se deixar disciplinarizar, em alguma medida, e é também dispor e ser atrevassada pela linguagem e repertório dos direitos. Taniele Rui e Fábio Mallart destacam uma observação na trama entre "Cracolândia" e cadeias de detenção provisória que incita-nos a conjugar a disciplinarização que ocorre nesse circuito - entre rua e equipamentos

14 (...) são criaturas inacabadas, ainda em estado de névoa. (...) não pertencem a nenhum dos outros grupos de personagens e não são estranhos a nenhum deles - são mensageiros que circulam entre todos. (...). Sua ambição era... ocupar um mínimo de espaço, e para isso, sempre sussurrando e rindo, faziam várias experiências, cruzavam seus braços e pernas, (...) na penumbra pareciam um grande novelo. Para eles e seus semelhantes, os inábeis e inacabados, ainda existe esperança” (Benjamin, 1987 [1934], p.142). 
assistenciais, de saúde e confinamento - a esse repertório: uma assistente social do lugar, por exemplo, valoriza usuários que já passaram por "cadeias PCC" porque são disciplinados, assim, é muito provável que causarão menos problemas, caso obtenham uma vaga no albergue (Rui; Mallart, 2017). Na rede da Assistência Social também ocorria algo próximo, usuárias reincidentes conhecidas na rede por suas histórias de vida e, em alguma medida, habituados a rotina e regras dos abrigos, eram tratados com maior tolerância e parcimônia.

Da mesma forma, Vanda modula fronteiras menos duras sobre o corpo "pestilento", da sífilis, tuberculose, HIV, DSTs, mas também um corpo passível de controle, igualmente capaz de disciplinarização para acessar direito que servirão na arte de contornar a vida nua, a vida matável. Não se proíbe a junção de camas, mas quem o faz não pode exagerar quanto a incomodar as outras parceiras de quarto; e ainda, precisa cuidar das partes íntimas, precisa cuidar da saúde, endossando as tentativas do abrigo de referenciar usuárias e seus tratamentos a equipamentos de atenção à saúde básica. E acessar direitos para contornar a vida matável também pode significar - como assinala Flora, a diretora - uma ampla dose de coragem; funcionam como revivificações de Antígona, a mulher-assombro que se nega a obedecer a lei do soberano de não enterrar o seu irmão, e ao fazer isso demonstra que, além da cidade e da história, a lei, o poder e o esquecer não estão pacificados (Butler, 2014): novas forças e rupturas são capazes de rever as posições de poder, as palavras de ordem, outras subjetividades capazes de ganhar consistência. Mas o que essa lei, o poder e o esquecer não pacificados contam da história das mulheres pobres e negras em um país periférico?

Acusações morais no rastro das revivificações de Antígona assombram o presente. Flora narra para mim que Raiana, que chegara aquela semana, foi parar no abrigo depois que brigou em um hotel na Central do Brasil. Ela estava fazendo programa, o cliente já havia pago, mas quando ela repara que "o pau estava muito babão" se negou a continuar. O cliente a ameaçou, Raiana se manteve firme, não devolveria o dinheiro, discutem, ela termina por chamar a polícia (sempre há uma viatura na esquina da rua principal da Central), a contenda foi dissolvida. "Menina, que garota corajosa!" - repetia Flora enquanto narrava a estória. Vale um breve contraponto a uma possível e esperada idealização de Raiana. Uma parcela da coragem de Raiana atém-se ao fato de que o espaço é protegido pela polícia, rumores dizem que isso acontece a pedido dos comerciantes locais, o que inclui também os donos de hoteis/moteis a custo módico e por frações espalhados por várias das ruas dali.

Nessa governança dos pobres, em especial, nessa governança das mulheres pobres e de seus corpos estariam sobrepostos dois regimes: o regime disciplinar das 
corporeidades femininas dissonantes, de modulação e controle do corpo pestilento que se excede, mas também apropriações e composições, um fazer-se no Estado (Aguião, 2018) por parte dessa população dos dispositivos de controle atravessado pelo repertório das políticas sociais, securitários, de saúde, religiosos, de assistência e terapêuticas ${ }^{15}$. E também como uma tentativa de se proteger das várias formas de violência da lei masculinista do Estado sobre suas existências (Vianna, 2014).

Brenda ao ameaçar chamar o Conselho Tutelar para denunciar que a filha estava vivendo em um "ambiente insalubre" buscava uma chance de voltar a visitar a filha que havia crescido e de retomar os laços com ela; Marli está no abrigo porque precisa se tratar e também é ali que poderá retomar o contato com a família, para quem sabe voltar a viver com a filha e seguir em seus tratamentos que devem durar para sempre; Simone desejava, por meio das políticas de proteção às pessoas em situação de vulnerabilidade social, resguardar os filhos e também retomar a vida conseguindo uma vaga com ajuda dos contatos e chances (não muitas) que o abrigo disponibilizava; por fim, Mônica, que exige ficar no abrigo e ao acessar as políticas de saúde para mulheres e deficientes recoloca a pauta do erotismo e da sexualidade e da maternidade nos corpos femininos como direito, mas na prática biomédica ainda é um corpo "mostruoso", "degenerado", "incapaz", nesse caso, as políticas públicas de saúde para deficientes são tensionadas pelos enunciados de Mônica - "não sou virgem", "estou grávida" e pelo desejo de viver sob a tutela do estado, o que não significa fazer da vida algo sem agência.

No caso do fazer-se no Estado pelos abrigos/assistência, uma corporeidade por gênero e contabilizada pelo que é considerado excesso. O excesso de coragem: uma coragem medida, remediada, pesada, no sentido de reinvindicar e afirmar outras formas de inscrição de gênero e de sexualidade, "a mulher barraqueira que exige direitos", "a mulher deficiente, mas sexualizada e erótica”, "a mulher pobre que ama demais"; o excesso da fuga: que pode significar retornar a uma condição material muito precária e que ameaça a própria existência, como o "cair na vida de Brenda"; por último, sem ser menor importante, o excesso do regime de poder: via coerção, coação, punição, violência física e morte, empenhados em conter suas demandas e afirmação de existência, e funcionar para evitar o contágio de outros corpos pela sede de direitos e reparações.

15 Várias pesquisas têm se debruçado sobre esses dispositivos, cito duas coletâneas que a meu ver continuam atuais, uma organizadas por Cabanes; Georges; Rizek; Telles (2011), a outra foi organizada por Birman, Patricia; Leite, Marcia; Machado, Carly; Carneiro, Sandra (2015). Sobre dispositivos religiosos associados a formas de controle territoriais e morais, remeto a Machado (2017); sobre dispositivos sociais nos anos do Lulismo, ver Georges e Santos (2016). Além destes, os artigos de Veena Das (2015) em Affliction: health, disease, poverty são uma referência fundamental sobre o assunto, o livro infelizmente encontra-se sem tradução no Brasil. 


\section{Referências}

AGAMBEN, Giorgio. Homo Sacer: o poder soberano e a vida nua I. Belo Horizonte, UFMG, 2004.

AGUIÃO, Silvia. Fazer-se no Estado. Uma etnografia sobre o processo de constituição dos LGBT como sujeitos de direitos no Brasil Contemporâneo. Rio de Janeiro, EdUERJ, 2018.

BATALHA, Elisa. Violência contra a mulher é problema do agressor e da sociedade inteira. Entrevista com Ana Flavia de Oliveira. Radis, 152, maio, 2015. Rio de Janeiro, ENSP/Fiocruz, pp. 13-15.

BENJAMIN, Walter. Franz Kafka: a propósito do décimo aniversário de sua morte. In Obras escolhi-das I. Magia e técnica, arte e política. São Paulo, Brasiliense, 1987 [1934], pp. 137-164.

BIRMAN, Patricia. Ocupações: territórios em disputa, gêneros e a construção de espaços comuns. In BIRMAN, Patricia, MACHADO, Carly. LEITE, Marcia Pereira; CARNEIRO, Sandra de Sá (orgs.). Dispositivos Urbanos e trama dos viventes: ordens e resistências. Rio de Janeiro, FGV, 2015.

BIRMAN, Patricia; Machado, Carly. A Violência dos Justos: evangélicos, mídia e periferias da metrópole. Revista Brasileira de Ciências Sociais, v. 27, n. 80, out. 2012.

BIRMAN, Patricia. Assistências governamentais, precariedades, gêneros e trajetórias. Projeto CNPq, 2018.

BIRMAN, Patricia. Narrativas seculares e religiosas sobre a violência: as fronteiras do humano no governo dos pobres. Sociologia e Antropologia, Rio de Janeiro, v. 9, n. 1, 2019, pp. 111-134.

BRETAS, Marcos Luiz. Cáp. A polícia e as mulheres. In: Ordem na cidade: 0 exercício cotidiano da autoridade policial no Rio de Janeiro: 1907-1930. Rio de Janeiro, Rocco, 1997.

BUTLER, Judith. O clamor de Antígona. Florianópolis, Editora UFSC, 2014.

CABANES, Robert; Georges, Isabel; Rizek, Cibele; Telles, Vera (orgs.). Saídas de Emergência. Ganhar/Perder a vida nas periferias de São Paulo. São Paulo, Boitempo, 2011.

CANGUILHEM, Georges. Escritos sobre a medicina. Rio de Janeiro, Forense Universidade, 2005.

CARRARA, Sérgio. Moralidades, racionalidades e políticas sexuais no Brasil contemporâneo. Mana, v. 21, n. 2, 2015, pp. 323-345.

CARRICONDE, Raquel. "Cair na rede”: Circulações desde os abrigos da cidade. Tese de doutorado. PPCIS/UERJ, 2019.

CHALHOUB, Sidney. Cidade Febril. Cortiços e epidemias na corte imperial. São Paulo, Companhia das Letras, 1996. 
CHATERJEE, Partha. The politics of the governed: reflection on popular politics in most of the world. New York, Columbia University Press, 2004.

CORTES, Mariana. O mercado pentecostal de pregações e testemunhos: formas de gestão do sofrimento. Religião e Sociedade. Dossiê Religião e Mídia. Religião e Sociedade, v. 34, n. 2, 2014.

COSTA, Jurandir Freire da. Ordem médica e norma familiar. Rio de Janeiro, Graal, 1979. . História da psiquiatria no Brasil: um corte ideológico. Rio de Janeiro, Editora Campus, 1980.

CUNHA, Flavia Melo da. Notas sobre "vulnerabilidade" e "proteção social” na tríplice fronteira Brasil-Peru- Colômbia. Comunicação. XVIII Congresso de Sociologia, GT 07 - Fronteiras e deslocamentos: o fazer sociológico nos espaços fronteiriços. Brasília, 2017.

DAS, Veena; RANDERIA, Shalini. Politics of the urban poor: aesthetics, ethics, volatiliy, precarity. In: Current Anthropology v. 56, n. 11, 2015, pp. 3-14.

DAS, Veena. Ordinary ethics in Fassin, Didier (org.). A Companion to moral anthropology. West Sussex, Inglaterra, John Wiley \& Sons Inc, 2012.

DAS, Veena. Affliction. Health, Disease, Poverty. New York, Fordham University Press, 2015, pp. 133-149.

DISTÚRBIO (grupo de pesquisa UERJ/UFRRJ). Projeto do grupo de pesquisa. Selecionado pelo Edital Humanidades/Faperj, 2016.

DONZELOT, Jacques. A polícia das famílias. Rio de Janeiro, Edições Graal, 1986.

DUARTE, Luis Fernando Dias. O nervosismo como categoria nosográfica no começo do século XX. História, Ciências, Saúde - Manguinhos, Rio de Janeiro, v. 17, n. 2, dez. 2010, pp. 313-326.

ENGEL, Magali. Psiquiatria e feminilidade. In: DEL PRIORE, Mary (org.) História das mulheres no Brasil. São Paulo, Contexto, 2004, pp. 270-297.

FASSIN, Didier. Compaixão e repressão: a economia moral das políticas de imigração na França. Ponto Urbe, 15, 2014, pp. 1-27.

FERREIRA, Mariana. Direitos humanos e psicologia: sobre cascas, feridas e lampejos em Experiências em psicologia e direitos humanos. Conselho Regional de Psicologia do Rio de Janeiro (1 $1^{\circ}$ lugar, Prêmio Beatriz Sá Leitão, 2016). Caderno Anual, n. 2, ano 2017.

FERNANDES, Adriana. Escuta ocupação: arte do contornamento, viração e precariedade no Rio de Janeiro. Tese de doutorado, PPCIS/UERJ, 2013.

Quando os vulneráveis entram em cena: Estado, vínculos e precariedade em abrigos. In: BARROS, Joana; COSTA, André Dal'bó da; RIZEK, Cibele (orgs.). Os limites da acumulação. Movimentos e resistência nos territórios. São Carlos, IAU/ USP, 2018, pp. 85-99. 
FERNANDES, Camila. Figuras da causação: sexualidade feminina, reprodução e acusações no discurso popular e nas políticas de Estado. Tese de doutorado, PPGAS/ MN/UFRJ, 2017.

FONSECA, Claudia. Ser mulher, mãe e pobre no Brasil. In: DEL PRIORE, Mary (org.). História das mulheres no Brasil. São Paulo, Contexto, 2004, pp. 428-463.

FOUCAULT, Michel. Os anormais. São Paulo, Martins Fontes, 2010.

. História da Sexualidade I: a Vontade de Saber. Trad. Thereza Albuquerque e J. Guillon Albuquerque. Rio de Janeiro, Graal, 1985.

. A vida dos homens infames. In: . O que é um autor? Trad. Antonio Cascais e Edmundo Cordeiro. Lisboa, Passagens e Vega, s/d, pp. 96-97.

GEORGES, Isabel; Santos, Yumi Garcia. As novas políticas sociais brasileiras na Saúde e na Assistência. Produção local do serviço e relações de gênero. Belo Horizonte, Fino Traço, 2016.

GUIMARÃES, Carmen Dora. Mais merece: o estigma da infecção sexual do HIV/AIDS em mulheres. Estudos Feministas, v. 4, n. 2, 1996.

DOUGLAS, Mary; ISHERWOOD, Baron. $O$ mundo dos bens: para uma antropologia do consumo. Rio de Janeiro, Editora UFRJ, 2009.

JARDIM, Fabiana. Pobreza e cidadania no Brasil (1985-2015): olhares a partir das relações entre trabalho e educação. Cadernos de Psicologia Social do Trabalho, v. 20, n. 2, 2017, pp. 187-201.

LAUGIER, Sandra. La vulnerabilité des formes de vie in Raisons politiques. n. 57, 2015/1, pp. $65-80$.

LIMA, Nisia; Hoschman, Gilberto. Condenado pela raça, absolvido pela medicina: o Brasil descoberto pelo movimento sanitarista da Primeira República. In: Chor, Marcos; Ventura, Ricardo (orgs.). Raça, ciência e sociedade. Rio de Janeiro, Fiocruz/ CCBB, 1996, pp. 23-40.

LOBO, Lilia Ferreira. Os infames da história: pobres, escravos e deficientes no Brasil. Rio de Janeiro, Lamparina, 2008.

LOPES, Myriam Bahia. O Rio em movimento. Quadros médicos em história (18901920). Rio de Janeiro, Editora Fiocruz, 2000.

MACHADO, Carly. Conexões e rupturas urbanas. Projetos, populações e territórios em disputa. Revista Brasileira de Ciências Sociais, v. 32, n. 93, 2017, pp. 2-21.

MIAGUSKO, Edson; Jardim, Fabiana; Cortes, Mariana. Governo, gestão de populações e subjetividades: balanço e perspectivas analíticas. Revista Brasileira de Sociologia, v. 6, n. 12, 2018. http://www.sbsociologia.com.br/revista/index.php/RBS/article/ view/242

PEREIRA, Milena Cassal; Ribeiro, Fernanda Bittencourt. No areal das mulheres: um benefício em família. Política e Trabalho, n. 38, abril 2013, pp. 87-104. 
RAGO, Margareth. Do cabaré ao lar: a utopia da cidade disciplinar (1890-1930). Rio de Janeiro, Paz e terra, 1997 [1985].

RUI, Taniele; Mallart, Fabio. Cadeia ping-pong: entre o fora e o dentro das muralhas. Ponto Urbe (no prelo), 2017.

PADOVANI, Natália. Casos e casamentos. Afetos e amores através de penitenciárias em Barcelona e São Paulo. Tese de doutorado, PPGAS/UNICAMP, 2015.

PIEROBON, Camila. Tempos que duram, lutas que não acabam: o cotidiano de Leonor e sua ética de combate. Tese de doutorado, Rio de Janeiro, PPCIS/UERJ, 2015.

SCABIO, Jeferson. Não dá para amarrar: uma etnografia da interação entre agentes de saúde e usuários de crack a partir do Consultório na rua. Dissertação de mestrado, PPGSA/UFRJ, 2013.

STEPAN, Nancy. Eugenia no Brasil, 1917-1940. In: Hochman, Gilberto; Armus, Diego. (orgs). Cuidar, controlar, curar: ensaios históricos sobre saúde e doença na América Latina e Caribe [online]. Rio de Janeiro, Editora Fiocruz, 2004. pp. 330-391.

SEYFERTH, Giralda. Construindo a nação: hierarquias raciais e o papel do racismo na política de imigração e colonização. In: Chor, Marcos; Ventura, Ricardo (orgs.). Raça, ciência e sociedade. Rio de Janeiro, Fiocruz/CCBB, 1996, pp. 41-58.

SOIHET, Rachel. Mulheres pobres e violência no Brasil urbano. In: DEL PRIORE, Mary (org.). História das mulheres no Brasil. São Paulo, Contexto, 2004.

TELLES, Vera. A cidade nas fronteiras do legal e ilegal. Belo Horizonte, Argumentum, 2010. , Vera. Direitos Sociais. Afinal de que se trata? Belo Horizonte, UFMG, 1999.

VIANNA, Adriana. Violência, Estado e Gênero: considerações sobre corpos e corpus entrecruzados. In.: SOUZA LIMA, Antonio Carlos de; GARCÍA-ACOSTA, Virginia. (Orgs.) Margens da Violência: subsídios ao estudo do problema da violência nos contextos mexicano e brasileiro. Brasília, ABA, 2014, pp. 209-237.

Introdução: fazendo e desfazendo inquietudes no mundo dos direitos. In: VIANNA, Adriana. (org.) O fazer e o desfazer dos direitos. Rio de Janeiro, E-papers, 2013.

Recebido em: 12/06/2019

Aprovado em: 06/12/2019

\section{Como citar este artigo:}

FERNANDES, Adriana. Mulheres pobres que amam demais: a vida dos direitos e das políticas sociais. Contemporânea - Revista de Sociologia da UFSCar, v. 9, n. 3, set.dez. 2019, pp. 745-770. 